\title{
REQUIREMENT OF ALPHA-RECEPTOR BLOCKADE FOR PRODUCTION OF HYPERURICEMIA IN THE RAT SUBJECTED TO ETHER STRESS
}

\author{
Takahiko SUMI and Yuri UMEDA \\ Division of Psychopharmacology, Psychiatric Research Institute of Tokyo, \\ 2-1-8 Kamikitazawa, Setagaya-ku, Tokyo 156, Japan \\ Accepted February 14, 1979
}

We recently reported that a hyperuricemia associated with a rise of plasma allantoin is produced in the rat by i.v. infusion of epinephrine (1) and by acceleration of adrenalepinephrine release following ventromedial hypothalamic stimulation $(2,3)$. These results suggest the development of hyperuricemia in response to various stress-stimuli. However, there are discrepancies in the results on the hyperuricemic response to the stress $(4,5)$. In the course of our studies, we found that the ether stress alone does not induce hyperuricemia in the rat but, after treating the animal with alpha-blockers, a marked hyperuricemia is elicited: this will be described in the present communication together with an explaination concerning the role of adrenal epinephrine in this stress-induced hyperuricemia.

Male Wistar rats weighing $250-300 \mathrm{~g}$ were given an ordinary laboratory chow diet and water ad libitum. Under pentobarbital anesthesia, a polyethylene catheter was chronically implanted into the abdominal aorta (1). Immediately after the cannulation, bilateral adrenal demedullation or sham operation from the dorsal approach was carried out with the animal still under anesthesia. Conscious rats were used for the experiments 3-5 days after the last surgery. Blood samples were withdrawn at intervals from the cannulated artery. Plasma from the sampled blood was collected and was next deproteinized (1). Uric acid and allantoin in the deproteinized plasma were measured by the uricase-peroxidase method (6) and by the glyoxylate reductase method (7) respectively.

Figure 1 shows the changes of plasma uric acid and allantoin when exposing the rat to a concentrated vapor of diethyl ether for 2-3 min with or without pre-treatment of the animal with phentolamine or phenoxybenzamine, each of which alone had no effect on the basal levels of either metabolites. The ether exposure alone did not alter the plasma levels of the purine metabolites. However, after the phentolamine treatment ( $2 \mathrm{mg} / \mathrm{kg}$, s.c.), plasma uric acid markedly increased in response to the ether stress. Phenoxybenzamine (40 $\mathrm{mg} / \mathrm{kg}$, s.c.) was also effective although the degree of the uric acid increment was less pronounced. In both these cases, plasma allantoin also tended to increase following the increase in uric acid. These results indicate that the ether stress alone does not increase the plasma levels of uric acid without simultaneous blockade of alpha-receptors.

Effect of bilateral adrenal demedullation or propranolol was next studied in an attempt 
to determine the role of adrenal epinephrine in this stress-induced response in the phentolamine-treated rat. In this experiment, the rat underwent the following treatment(s) before the ether exposure: one group of animals was subjected to bilateral adrenal demedullation or sham operation, and was then given phentolamine $(2 \mathrm{mg} / \mathrm{kg}, \mathrm{s.c}$.); another group was given a mixed solution containing propranolol $(5 \mathrm{mg} / \mathrm{kg})$ and phentolamine $(2 \mathrm{mg} / \mathrm{kg})$ s.c. None of these three pre-treatments had any effects on the basal levels of uric acid. As shown in Fig. 2, while there was a stress-induced increase in plasma uric acid and allantoin in the sham-operated rat given phentolamine, as was the case in the intact rat, adrenal demedullation completely abolished these responses. This result indicates that the increase in plasma purine metabolites in response to the stress are dependent solely on the adrenal medulla. Moreover, propranolol also abolished the stress-induced responses in the phentolamine-treated rat. Such findings are consistent with those reported in a previous paper that rises in levels of plasma uric acid and allantoin are elicited by the stimulation of betareceptors (1).
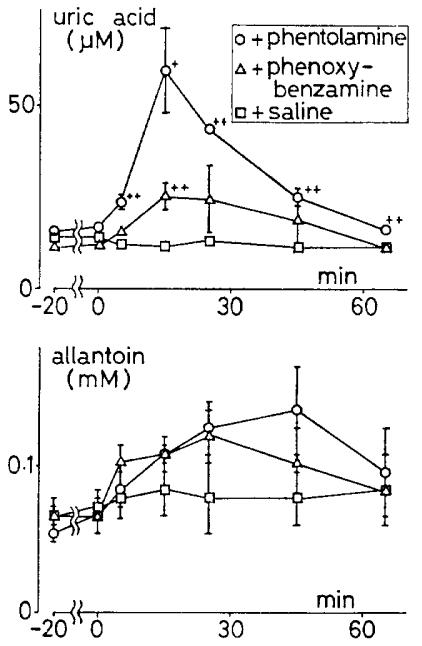

FIG. 1. Effects of ether-induced stress on the plasma levels of uric acid and allantoin in the normal and the phentolamine or phenoxybenzamine-treated rat. Saline, phentolamine $(2 \mathrm{mg} / \mathrm{kg}$ ) or phenoxybenzamine $(40 \mathrm{mg} / \mathrm{kg}$ ) was injected s.c. $20 \mathrm{~min}$ before exposing the rat to a concentrated vapor of diethyl ether for 2-3 min. The ether exposure began at time 0 . Each point is mean \pm S.E. of $4-5$ animals. The data were analyzed statistically using Student $t$-test; significant difference from value of the saline-injected rat is indicated with $+(\mathrm{P}<0.05)$ or $++(\mathrm{P}<0.01)$.
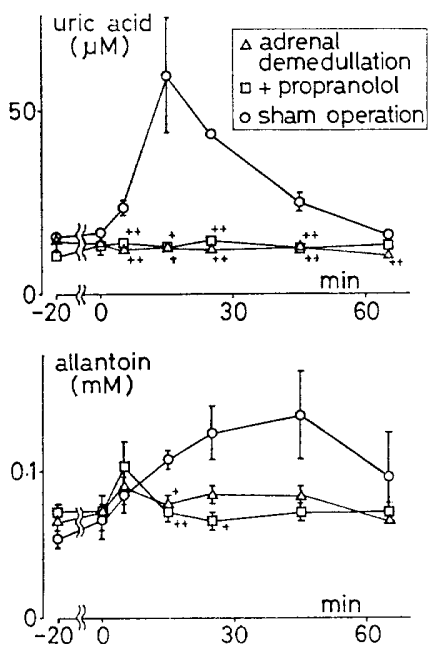

FIG. 2. Effects of adrenal demedullation or propranolol on the ether stress-induced rises of plasma uric acid and allantoin in the phentolamine-treated rat. Intact, adrenal demedullated and sham operated rat were given phentolamine $(2 \mathrm{mg} / \mathrm{kg}$, s.c.) $20 \mathrm{~min}$ before exposure to a concentrated vapor of diethyl ether for 2-3 min. Simultaneously with this injection, the intact rat was also given propranolol $(5 \mathrm{mg} / \mathrm{kg}$, s.c.). The ether exposure began at time 0 . Each point is mean \pm S.E. of 4 animals. The data were analyzed statistically using Student $t$-test; significant difference from value of the sham operated rat is indicated with $+(\mathbf{P}<0.05)$ or $++(\mathbf{P}<0.01)$. 
The present results showed that ether stress alone did not induce a hyperuricemia in the rat whereas, after treating the animal with an alpha-blocker, phentolamine or phenoxybenzamine, plasma uric acid as well as allantoin markedly increased in response to the stress (Fig. 1). The following evidence supports the idea that adrenal epinephrine plays a major role in the stress induced hyperuricemia: (A) adrenal demedullation abolished this response (Fig. 1); (B) propranolol eliminated both the hyperuricemia induced by the ether stress (Fig. 2) and by the infusion of epinephrine (1); (C) norepinephrine had no effect on the plasma purine metabolites (1). It can be concluded therefore that while the enhancement of adrenal epinephrine release is capable of producing a hyperuricemia, such does not actually occur without simultaneous blockade of alpha-receptors.

Studies have been done on the influence of catecholamines on purine metabolism $(8,9)$, however, there has been no direct evidence to show the involvement of adrenergic receptors in the biochemical events leading to the production of hyperuricemia. Based on the hypothesis that the beta-receptor-mediating hyperuricemia is masked or inhibited by the stimulation of alpha-receptors (1), the present results may be explained by assuming that simultaneous stimulation of this inhibitory alpha-receptor completely suppressed the hyperuricemia induced by active beta-receptors during ether stress.

\section{REFERENCES}

1) SUmi, T. AND UmEDA, Y.: Adrenergic regulation of the plasma levels of purine metabolites in the rat. Europ. J. Pharmacol. 46, 243-247 (1977)

2) Sumi, T. And Umeda, Y.: Hyperuricemia in the rat following hypothalamic stimulation. Life Sci. 21, 1675-1678 (1977)

3) Sumi, T. And Umeda, Y.: Adrenal epinephrine in hyperuricemia induced by hypothalamic stimulation of the rat. Am. J. Physiol. 236, (1979) (in press)

4) Bishop, C. and Talbott, J.H.: Uric acid: its role in biological processes and the influence upon it of physiological, pathological and pharmacological agents. Pharmacol. Rev. $5,231-273(1953)$

5) Miller, S.P. AND Kuyper, A.C.: The relation of insulin and adrenalin to uric acid excretion in the rabbit. Am. J. Physiol. 123, 625-629 (1938)

6) Sumi, T., Umeda, Y., Kishi, Y., Takahashi, K. and Kakimoto, F.: The enzymatic spectrofluorometric determination of uric acid in microsamples of plasma by using p-hydroxyphenylacetic acid as a fluorophor. Clin. Chim. Acta 73, 233-239 (1976)

7) Sumi, T., Umeda, Y., Kishi, Y., Kakimoto, F. and Takahashi, K.: A spectrofluorometric method for determining plasma allantoin based on the glyoxylate reductase reaction. Analyt. Biochem. 75, 563-567 (1976)

8) Yonetani, Y., Ishi, M. and Yamada, K.: Origin of uric acid induced by 1-epinephrine. Chem. Pharm. Bull. 25, 457-463 (1977)

9) Lalannf, M. and Henderson, J.P.: Effects of hormones and drugs on phosphoribosyl pyrophosphate concentrations in mouse liver. Canad. J. Biochem. 53, 394-399 (1975) 